\title{
Retraction Note to: Biological Mechanisms Relating Periodontitis and Diabetes
}

\author{
Hatice Hasturk $^{1}$ • Alpdogan Kantarci ${ }^{1}$
}

Published online: 26 October 2016

(C) Springer International Publishing AG 2016

Retraction Note to: Curr Oral Health Rep (2016) 3:282-292

DOI 10.1007/s40496-016-0100-4

At the request of the authors, this article has been retracted owing to incomplete authorship.

The online version of the original article can be found at doi: http://dx.doi. org/10.1007/s40496-016-0100-4.

Hatice Hasturk

hhasturk@forsyth.org

1 Forsyth Institute, Suite 1757, Cambridge, MA 02142, USA 